\title{
O ENSINO DE METODOLOGIA DE PROJETO ATRAVÉS DA CRIAÇÃO DE ÓCULOS INTERATIVOS
}

Júlio Alessi

UniBH - Centro Universitário de Belo Horizonte

juliolafeta@gmail.com

Akemi Ishihara Alessi

UniBH - Centro Universitário de Belo Horizonte

akemi.i.a@gmail.com

Resumo: $O$ presente artigo tem como objetivo analisar o ensino de metodologia de design a partir da prática, com o desenvolvimento do projeto - Óculos interativos. A proposta do projeto foi desenvolvida afim de que os alunos do segundo período do curso de Design, do Centro Universitário de Belo Horizonte, na disciplina Metodologia e Gestão de projetos, pudessem vivenciar a prática de uma metodologia projetual com pensamento sistêmico, na qual viessem a desenvolver, além de um produto inovador, uma experiência completa através do design. A partir da etapa da pesquisa de campo com usuários reais, foi possível criar um cronograma, fazer a previsão dos custos e propor a solução final. A ementa da disciplina prevê um aprendizado das práticas do design de forma a sistematizar o processo em busca de produtos inovadores com soluções criativas. O projeto foi desenvolvido para que os alunos aplicassem as teorias vistas e debatidas em sala de forma prática, compreendendo o papel da metodologia para o desenvolvimento de projetos de design. Serão apresentados nesse artigo, o referencial teórico, a metodologia utilizada e o resultado alcançado pelos alunos durante o decorrer do projeto.

Palavras-chave: Metodologia de projeto, Pensamento sistêmico, Prática projetual.

\section{Abstract:}

This article aims to analyze the design methodology of teaching from practice, with the development of the project - Interactive Glasses. The project proposal was developed for students of the second period of the course of Design, University Center of Belo Horizonte - UniBH in methodology and project management discipline, could experience the practice of architectural design methodology with systemic thinking, which came to develop, in addition to an innovative product, a complete experience through design. From the field research of step with actual users, it was possible to create a schedule, the anticipated costs and propose the final solution. The menu of course provides a learning 
experience of design practices in order to systematize the process of searching for innovative products with creative solutions. The project was developed so that students applied the views and theories discussed in practical room, including the role of the methodology for the development of design projects. They will be presented in this article, the theoretical framework, the methodology used and the results achieved by students during the course of the project.

Keywords: Design methodology, Systems thinking, Design practice.

\section{INTRODUÇÃO}

Os usuários tornaram-se mais incontentáveis, as mídias sociais Ihes propiciou o acesso às informações e a interação com outros usuários, transformando-os em prosumers $^{1}$ e ampliando este conceito de Tofler (1997). O ato de projetar ganhou novas dimensões e o sistema produtivo teve que sucumbir aos desejos desse novo consumidor pós-moderno em um mercado cada vez mais segmentado.

Este novo perfil de usuários conectados e engajados têm orientado as alternâncias produtivas ocorridas nos últimos anos. Situação que tende a se estender perceptivelmente, principalmente em função das mídias sociais, através das quais é possível sugerir mudanças em serviços e em produtos de forma participativa entre as empresas e seu prospect ${ }^{2}$. Essa interação tem levado os designers a reverem os métodos tradicionais utilizados na prática projetual.

Diante desse cenário a disciplina de metodologia projetual acaba sendo um importante elo entre a teoria e a prática, no pensar projetual do designer, para instigar e promover o envolvimento dos alunos com o pensar projetual foi desenvolvido o projeto: Óculos interativos. O objetivo geral foi instigar os alunos a trabalharem com um método de design não linear para a solução de problemas complexos, baixo custo e prazo controlado, através de um aprendizado lúdico e prazeroso. Os objetivos específicos do projeto visaram apresentar as etapas projetuais do método design thinking a partir de atividades práticas em sala, estendidas para a vivência extraacadêmica, viabilizando ao final de cada etapa uma reflexão teórica sobre as atividades desenvolvidas.

\section{DESENVOLVIMENTO}

Devido à complexidade teórica da disciplina e seu papel preponderante para a formação do designer, o grande desafio foi propor uma reflexão sobre a prática profissional do designer inserido em um novo contexto social, na qual o projeto deve contemplar uma demanda social integrada aos meios produtivos. Como desenvolver uma metodologia que cumpra esse novo papel do designer? Como instigar os alunos a

\footnotetext{
${ }^{1}$ Producer + Consumer, destaque do novo papel do consumidor atualmente que é exigente e influencia de forma direta a indústria a produzir aquilo que ele quer consumir.

2 "Indivíduo qualificado e interessado que, através de uma interação tipo "mão dupla", demonstrou estar preparado para uma decisão de compra." MAIA. Acesso em 10/07/2016 <http://www.neimaia.com/quais-as-diferencas-entre-leads-e-prospects/>
} 
se interessarem por tais conteúdos? E finalmente: Como adaptar o projeto ao cotidiano deles?

O atual cenário complexo e fluido é ideal para o caráter transdisciplinar inerente ao profissional de design, como ressalta Dijon (2009)

Os atributos tecnicistas até então predominantes eram lógicas pretensiosamente determinantes e lineares portadoras de soluções preestabelecidas que definiam o produto e a produção na era moderna, ao mesmo tempo que buscavam suprir de maneira uniforme, a grande massa consumidora humana. Mas a consequência do alargamento produtivo industrial, ocorrido a partir do final do século $X X$, foi a produção de bens de consumo esteticamente assemelhados, compostos de signos imprevisíveis e repletos de conteúdos frágeis, contrários aos princípios e aos fundamentos do design. (DIJON, 2009, p. 10)

A obviedade dos processos produtivos e a padronização propiciada pela revolução industrial sofreu uma ruptura com a pós-modernidade existente na modernidade. O pensamento linear e o confortável pensamento mecanicista com o método analítico de cindir o problema em partes e começar a resolvê-las é inaplicável num ambiente complexo com suas intensas variáveis e peculiaridades no cenário atual, nos quais os sistemas estão interligados.

A explicação não pode mais ser um esquema racionalizador. A ordem, a desordem, a potencialidade organizadora. Devem ser pensadas juntas, ao mesmo tempo, em seus caracteres antagônicos bem conhecidos e seus caracteres complementares bem desconhecidos. Esses termos se remetem um ao outro e formam uma espécie de circuito em movimento. Para concebê-lo, é preciso de princípio e de método. A questão da cosmogênese é, portanto, ao mesmo tempo, a questão-chave da gênese do método. (MORIN, 2008, p. 65)

Uma das características dos processos metodológicos atuais é a coparticipação de equipes multidisciplinares, o "Eu" perde espaço para o "Nós", sendo vital para o sucesso do projeto saber lidar com a diversidade proveniente do trabalho em equipe. Cada grupo pode definir um target ${ }^{3}$ o que propiciou afinidade e identificação com o perfil dos próprios alunos, ou seja, a aproximação do universo em que vivem o que culminou em maior envolvimento com o projeto.

Com o princípio do trabalho em equipe e cocriação, diante da possibilidade de atuar em etapas cambiantes e flexíveis que podem ser moldadas de acordo com os propósitos, o Design Thinking é um poderoso método para o desenvolvimento de projetos, Brown (2007) o define como:

O design thinking começa com habilidades que os designers têm aprendido ao longo de várias décadas na busca por estabelecer a correspondência entre as necessidades humanas com os recursos técnicos disponíveis considerando as restrições práticas dos negócios. Ao integrar o desejável do ponto de vista humano ao tecnológica e economicamente viável, os designers têm conseguido criar os produtos que usufruímos hoje. (BROWN, 2007, p.3)

\footnotetext{
${ }^{3}$ Público Alvo.
} 
O tema tecnologia foi escolhido para apresentar aos estudantes as possibilidades da profissão em desenvolver experiências inovadoras utilizando tecnologias já existentes ou emergentes. Considerando como uma oportunidade de conceber projetos em uma área em franco crescimento.

Durante o Encontro Sul-americano de Ensino em design, em Buenos Aires, em julho de 2015, foi possível comutar experiências didáticas com diversos colegas professores. Diversos apontamentos sobre a importância da prática no ensino de metodologia surgiram, reiterando que é comum encontrar relatos de alunos que veem a disciplina como algo chato e sem sentido, não conseguindo correlacionar a teoria com a prática.

\subsection{Design vernacular}

Para que os alunos pudessem discernir entre um design desenvolvido por leigos para a solução de problemas cotidianos e o trabalho concebido com a utilização de um processo metodológico, foi proposto um desafio de design vernacular. O conceito de Design vernacular correntemente é atribuído à produção de artefatos desvinculados do contexto acadêmico ou princípios industriais. Walker (2002), afirma que o Design vernacular está intrinsicamente ligado à criatividade e utilização de recursos restritos inerentes ao ambiente. São carregados de valores metafóricos com fortes vínculos com a cultura local, que suplantam as questões funcionais.

Os alunos foram divididos em grupos de 8 a 11 componentes e tiveram uma semana para pesquisar sobre o processo de criação de produtos por leigos através do design vernacular e tiveram que apresentar suas considerações teóricas com base nos estudos realizados. A apresentação da pesquisa teve que ser realizada através de cartazes feitos a mão, teatro, performance ou outra estratégia que não envolvesse a utilização de softwares ou apresentações digitais.

Após a apresentação eles foram submetidos a um desafio de transformar uma cabaça em um projeto de design vernacular para ser apresentado na outra semana. 0 objetivo desse primeiro projeto foi realizar a gestão do tempo e a execução de um projeto sem utilizar um método de design previamente definido. A biônica foi apresentada após as demonstrações das soluções, como o método que prevê o uso de recursos naturais ou estruturas naturais no desenvolvimento ou como inspiração para solução de projetos.

\subsection{Definição do público e suas necessidades}

Para a definição do público foram realizadas dinâmicas em sala e a construção de uma Buyer Persona ${ }^{4}$ os grupos desenvolveram personagens fictícios com características marcantes para servirem de inspiração para um nicho específico de mercado para o projeto dos óculos. Os personagens criados foram bem diversificados, tivemos um Geek, um homem aventureiro, uma Hipster (Figura 1), um estudante, um cego, um idoso e uma dona de casa.

\footnotetext{
${ }^{4}$ Byer Persona é uma ferramenta do marketing que após pesquisar o público alvo de um produto ou serviço, desenha-se o perfil comportamental desse cliente. Cria um nome fictício, uma foto e uma descrição de suas necessidades, desejos e interesses. A persona criada será um guia para a equipe que irá produzir o conteúdo, serviço ou produto.
} 


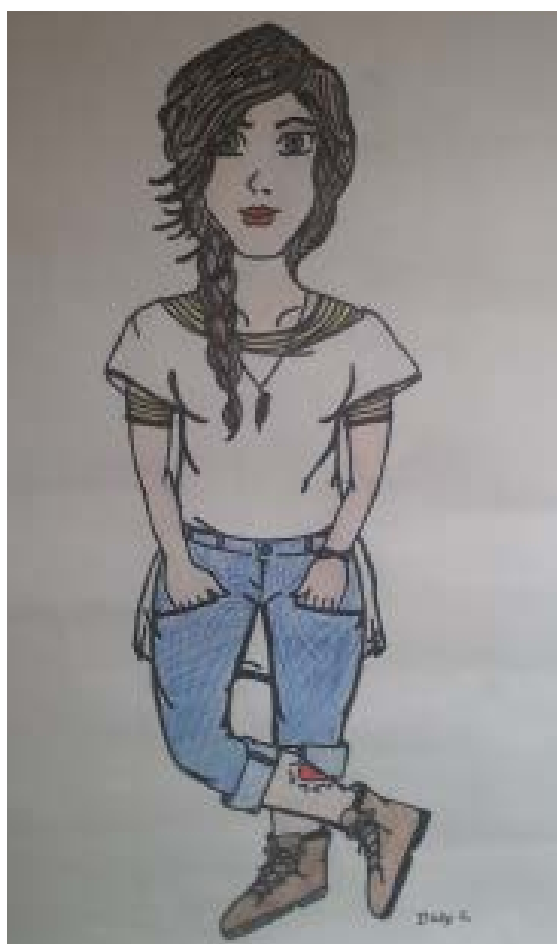

Figura 1 - llustração dos alunos para representar a Persona.

As alterações sociais, políticas e econômicas devem ser observadas pelo designer. Alterando os paradigmas e as relações entre os usuários e a indústria.

A globalização nos confronta o tempo todo com relações complexas. Encontrar oportunidades e situações de equilíbrio na relação localglobal é um grande desafio, especialmente no que se refere à melhoria das condições de qualidade de vida, à valorização e ao respeito da diversidade e do ecossistema, aos modelos de produção e de consumo. KRUCKEN, (2009, p.37)

Foram realizadas algumas atividades para conhecer melhor o público e levantar suas necessidades e oportunidades de projetos. As principais ferramentas utilizadas foram: grupo focal (com 8 participantes que representam o público pretendido, foram propostas perguntas de um questionário semiestruturado levando as pessoas a relatarem seus desejos, dificuldades e gostos pessoais); entrevista individual e em grupo, presencialmente e através do Facebook; e mapa mental (Figura 2) - os integrantes dos grupos fizeram as conexões entre as informações obtidas nas pesquisas com os usuários.

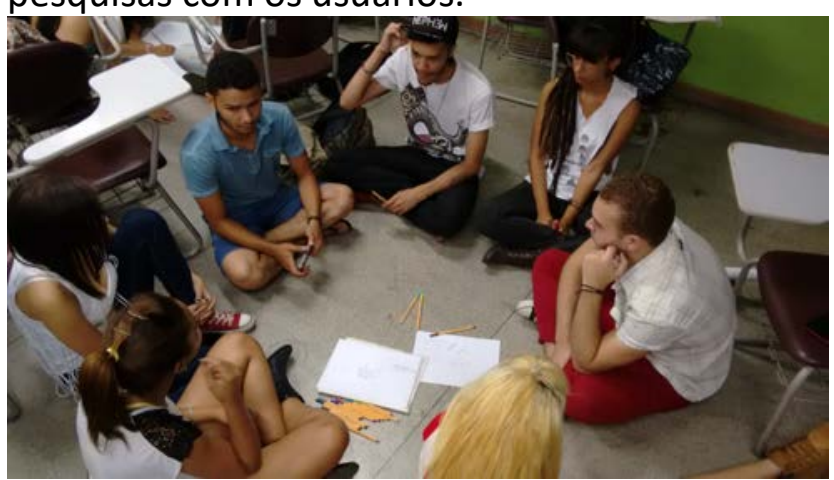

Figura 3 - Grupo de alunos realizando o mapa mental. 
Como viés teórico, foi apresentado aos estudantes como o designer faz uso de pesquisas com base etnográfica para desenvolver projetos com foco no usuário.

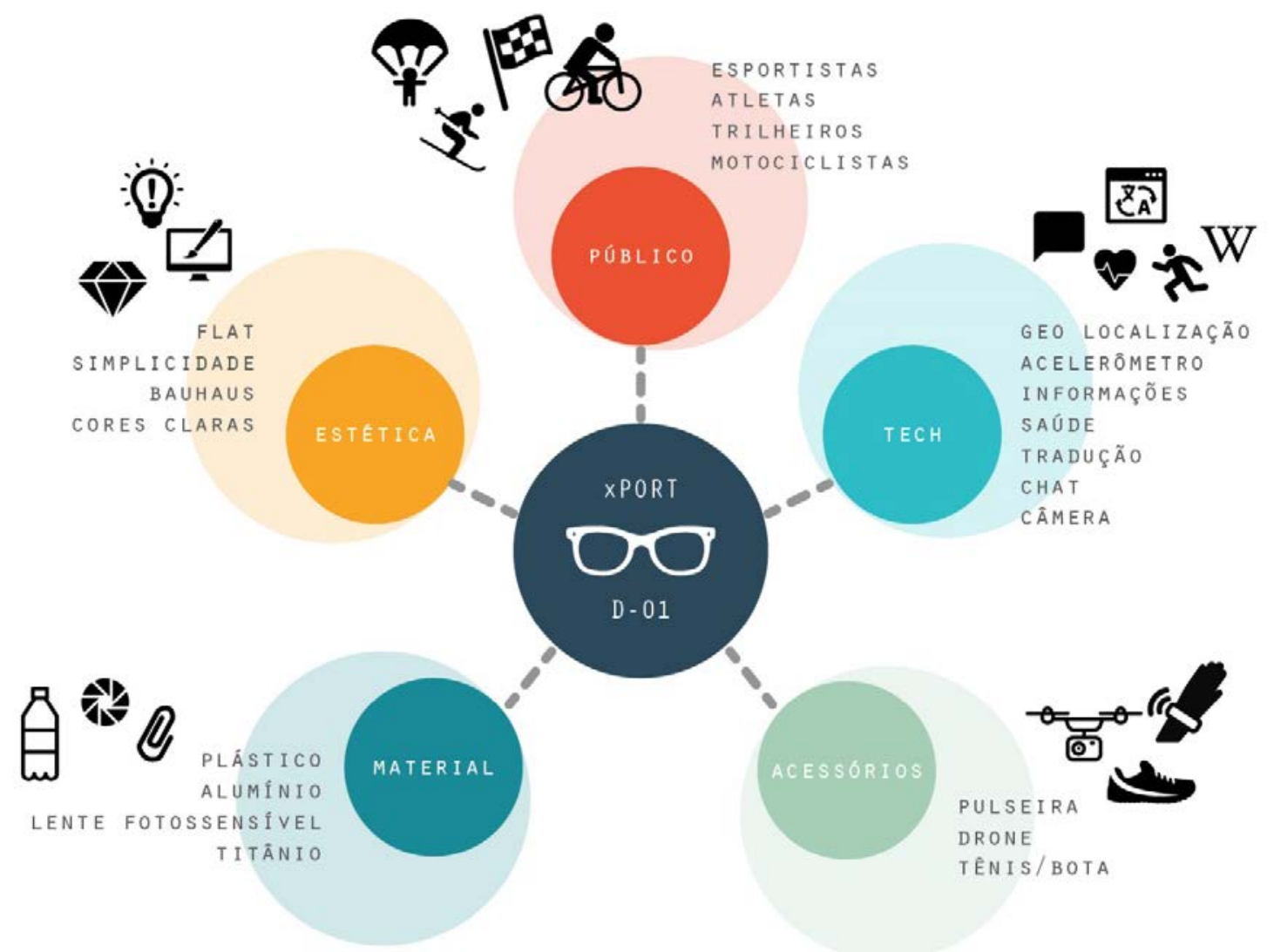

Figura 3 - Finalização do mapa mental de uma das propostas.

\subsection{Pesquisa, ideação, desenvolvimento e apresentação do projeto finalizado}

Através da análise dos resultados obtidos nas vivências e pesquisas sobre o público, cada grupo desenvolveu diversas ideias (Figura 4 e Figura 5) a serem aplicadas no projeto, fazendo uso de óculos interativos que atendessem uma demanda específica dos usuários.

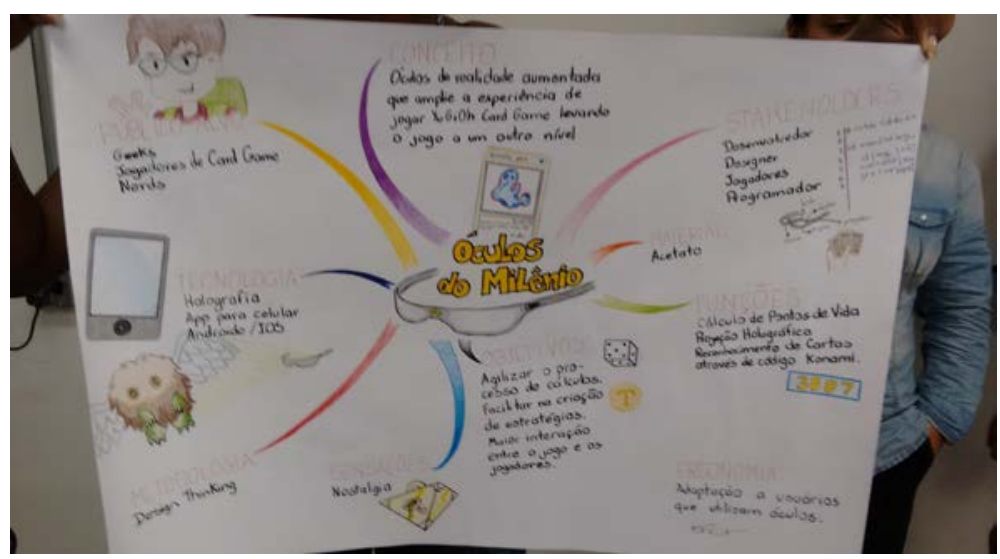

Figura 4 - Ideação - após as pesquisas os alunos idealizaram os projetos. 


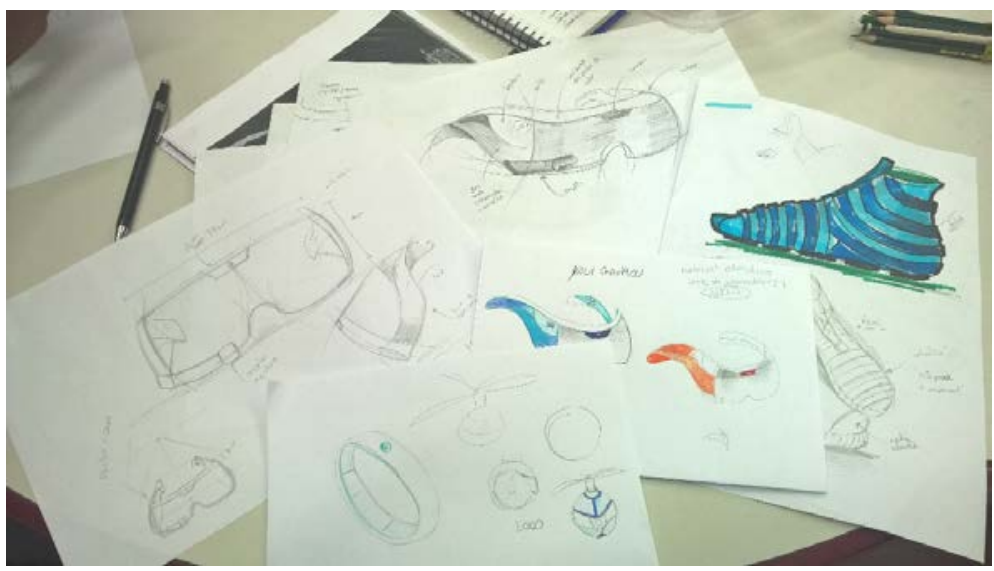

Figura 5 - desenvolvimento - após a ideação os alunos desenvolveram os projetos.

Para apresentar a ideia escolhida pelo grupo a ser desenvolvida, os alunos tiveram que criar um storyboard (Figura 6) demonstrando a experiência com os óculos criados para o público, no intuito de discutir possíveis falhas projetuais ou melhorias.

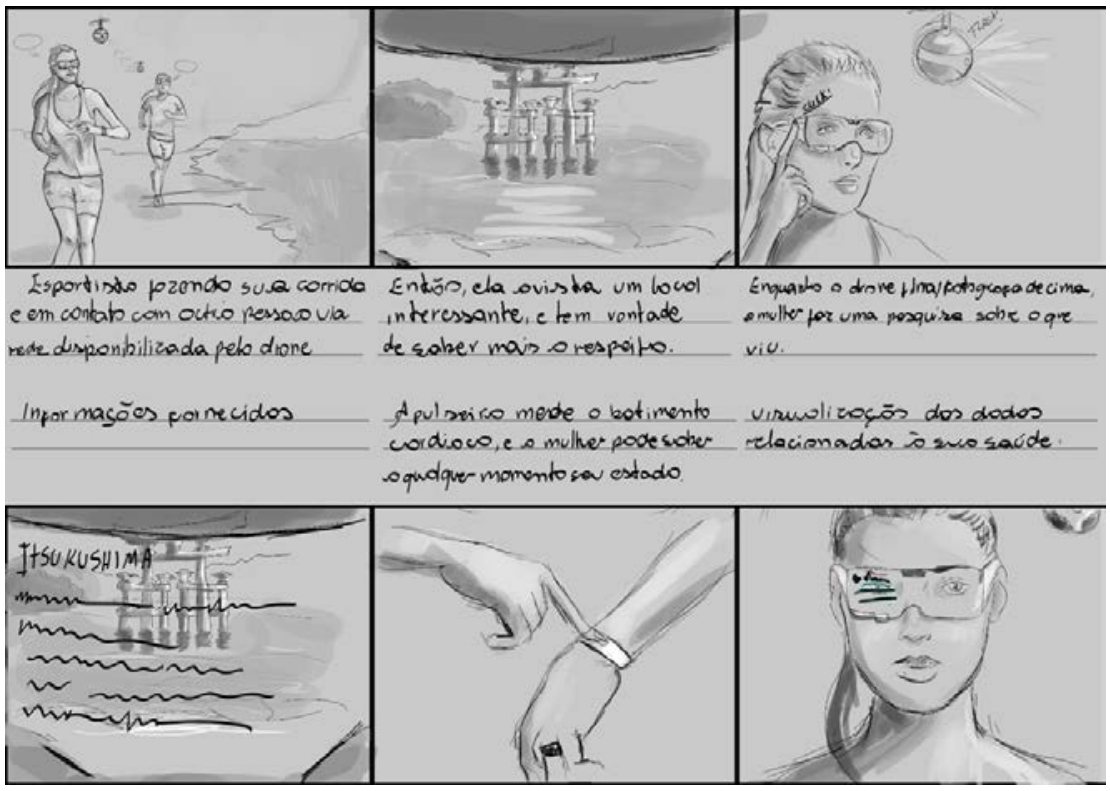

Figura 6 - Storyboard - um exemplo de como os alunos ilustraram o funcionamento dos óculos.

Os alunos analisaram em conjunto cada projeto, fazendo críticas e sugestões, o que resultou em uma ideia mais refinada culminando no projeto final.

Após finalizar o projeto, os grupos apresentaram o resultado através do storyboard acabado e de um rendering manual (Figura 7) dos óculos, para valorizar o desenho feito à mão desenvolvido na disciplina de desenho, promovendo a interdisciplinaridade. Cada grupo entregou um memorial descritivo do projeto contendo os detalhamentos técnicos e o registro de cada etapa empreendida para a execução do projeto. 


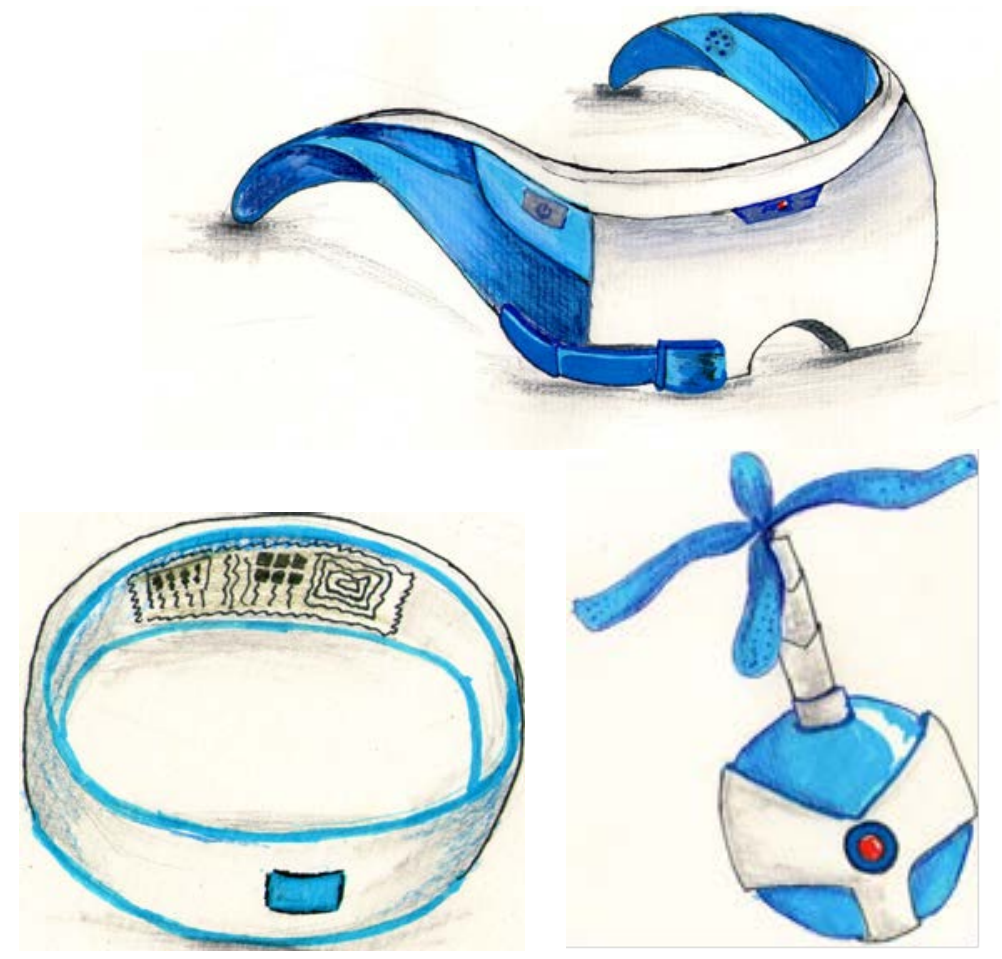

Figura 7 - rendering manual, interdisplinaridade e valorização do desenho à mão

No intuito de demonstrar o projeto de forma física foi desenvolvido uma impressão do projeto em uma impressora 3D (Figura 8).

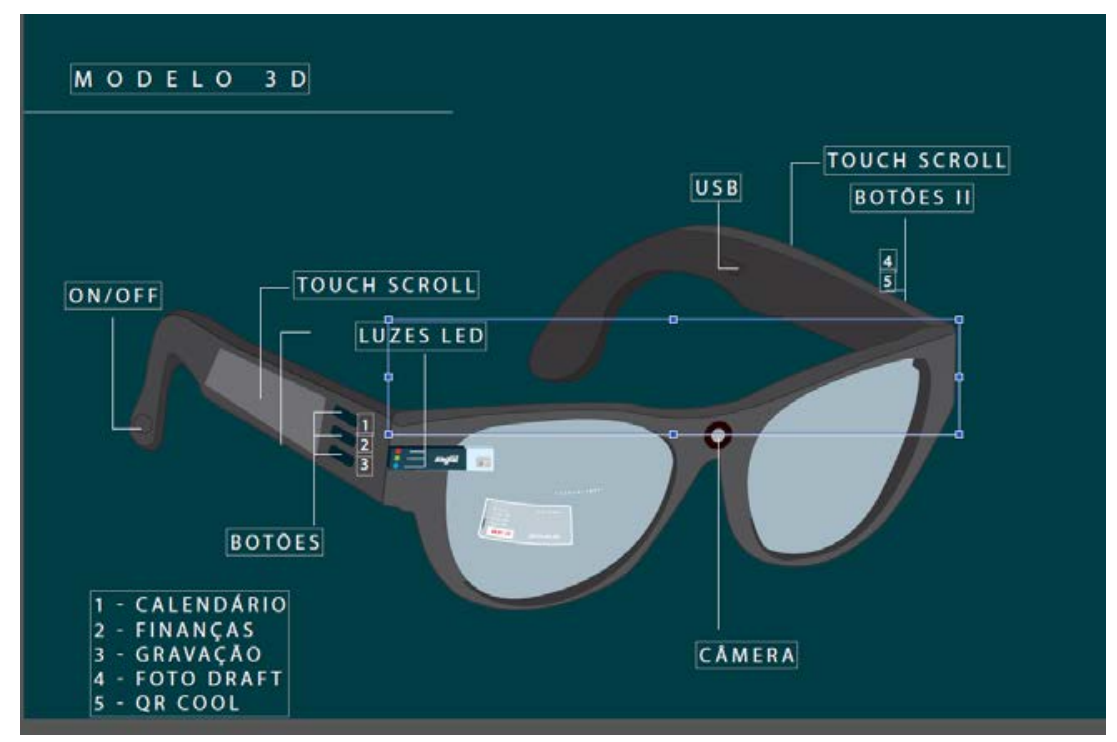

Figura 8 - detalhamento do projeto para a impressão 3D.

\subsection{Resultados}

Os óculos criados são oportunidades de negócios para nichos específicos com grande viabilidade mercadológica, sem contar a relevância social que eles propõem.

Foram criados seis óculos interativos sendo ${ }^{5}$ :

\footnotetext{
${ }^{5}$ A descrição dos óculos é de autoria dos alunos, optamos por deixar a descrição original de cada grupo devido à relevância conceitual na apresentação dos resultados obtidos.
} 
Xport - Foi projetado para esportistas, atletas e entusiastas do mundo de aventuras e esportes radicais. Um público bem específico que adora aparatos tecnológicos para interação ou busca de informação durante suas trilhas/aventuras. São óculos inteligentes (smart glasses) que interagem com o usuário, informando-o de aspectos do local, da sua condição física, informações gerais, chat, dentre outros recursos. Essa interação se dá através das lentes e dos botões capacitivos presentes no corpo do objeto.

Gadget - Contará com recursos de geolocalização (GPS), acelerômetro, acesso à internet, trará informações sobre os locais, informações sobre saúde do usuário e do grupo, serviço de tradução em tempo real e chat entre o grupo via rede. Como parte de um kit para a melhor experiência, será incluso uma série de acessórios para que a atividade se torne mais completa e agregue valor ao esporte e ao usuário. Dentre os acessórios, pode-se destacar: Pulseira inteligente, Drone e Tênis/Bota. A intenção é levar ao usuário uma experiência singular na prática de seus esportes favoritos.

Healthglass - Foi desenvolvido para atender a necessidades dos idosos que tenham problemas de saúde, ou que queiram ter uma vida mais saudável e gostariam de gerenciar suas atividades de forma simples e intuitiva. Os óculos possibilitam lembrar o usuário através de mensagem na tela o horário de tomar remédios; alerta sobre a qualidade nutricional básica dos alimentos que ele irá ingerir; faz um diário do consumo de alimentos, água e exercícios físicos realizados durante o dia; controla os batimentos cardíacos e um histórico de percursos realizados durante a semana.

Sagui - É um smart glasses focado nos alunos que utiliza a tecnologia para auxiliar no desenvolvimento da aprendizagem, gerando maior interação dos conteúdos propostos pelo professor em tempo real, auxiliando o estudante no gerenciamento do processo educacional como: calendário de atividades; matérias estudas; gravação de áudio das aulas para posterior estudo; fotografia do quadro com a matéria e captura Qr codes com links de vídeos para aprofundar nos conteúdos.

Hipstglaas - É um smart glasses que interage com conteúdos reais, reconhecendo imagens através de um banco de informações na plataforma do google e mostra os resultados na tela dos óculos.

Óculos do Milénio - São óculos focados no público Geek que ampliam a experiência de se jogar o game Yu-Gi-Oh, onde o usuário irá visualizar os personagens do game a partir de projeção holográfica; através de uma realidade aumentada, o jogador também poderá visualizar o cálculo de pontos de vida, dicas de jogadas, e invocação de personagens.

Labrador - O projeto Labrador consiste em um smart glasses que através de tecnologias de sensores de movimento, sensores de presença e geolocalização, auxilia os deficientes visuais em sua locomoção em ambientes internos e externos, gerando maior mobilidade sem a necessidade de um cão guia.

Stella - São óculos destinados às pessoas que tem como hábito a leitura, a noite antes de dormir. Ele conta com uma armação comum de óculos com um LED em cada ponto da parte superior frontal, proporcionando maior conforto ao usuário.

Óculos Scence - Foi pensado para a dinamicidade do cotidiano das pessoas. Scence, reminescence, reminiscência, o nome significa clareza e lembranças, que remete a guardar momentos, registro e memórias. Possui como função principal a interação de eventos e atividades com o registro, através de fotos. A principal argumentação, foi o porquê incluir uma câmera nos óculos, sendo que a câmera do 
celular cumpria essa função? Como resposta, veio a filosofia presente na frase "os olhos são a janela da alma", no qual percebe-se a ideia de ao retirar o celular do local guardado, perde-se tempo precioso da imagem que se deseja registrar naquele exato momento, em contrapartida, um dispositivo, próximo aos olhos será infinitamente mais capaz de registrar toda a intensidade presente num momento, seja por um passeio, momento familiar, romântico, paisagens ou ainda em festas e ocasiões cotidianas. Foram criados óculos que contém uma tecnologia avançada, trazendo praticidade ao utilizá-los pois terá agilidade e rapidez, reconhecendo que esse é um dos pontos mais valorosos que as pessoas procuram na hora da compra de um aparelho tecnológico.

O resultado final foram projetos inovadores que resultaram de um método de design bem definido e gerenciado pelos alunos que cumpriram os prazos propostos e conseguiram vivenciar a prática projetual de forma lúdica e prazerosa. Os alunos descreveram que o aprendizado de conteúdos densos e teóricos através de vivencias práticas facilita o processo educacional, instigando os estudantes a sair do lugar comum em busca de novas informações para sua formação profissional.

\section{CONCLUSÃO}

O melindre em transformar a metodologia em uma ciência padronizada pode ter resultado no equivocado tratamento do tema, como reforça Bonsiepe (2012), que durante o desenvolvimento da metodologia em design, algumas áreas do design não obtiveram o mesmo zelo na determinação de uma metodologia projetual.

Os métodos devem ser pesquisados, assim como as técnicas de criação para que o designer possa projetar sua metodologia e definir técnicas e ferramentas para a prática do design. O que leva à conclusão de que a metodologia, apesar de não ser uma receita de bolo, deve ser entendida como importante etapa no processo e que o designer deve possuir plena consciência do planejar antes do executar, desenvolver o pensar projetual concomitante à prática projetual.

O resultado do projeto foi surpreendente pois mesmo em uma turma com mais de sessenta alunos, o envolvimento, tempo e energia gastos foi muito grande, tanto nas práticas quanto nas reflexões teóricas. Como resultado, vários projetos exequíveis e de grande viabilidade técnica, conceitual, ergonômica e estética. Em relação ao processo de ensino aprendizagem foi possível mensurar a retenção do conhecimento teórico dos conteúdos abordados na disciplina através do desempenho apresentado por eles nas Avaliações Finais, nas quais obtiveram notas acima da média atingida em outros semestres. Os alunos atingiram resultados positivos, demonstrando assim que práticas pedagógicas que se adaptam ao perfil dos alunos propiciam excelentes resultados práticos e teóricos.

\section{REFERÊNCIAS}

BISTAGNINO, Luigi. Design sistêmico: uma abordagem interdisciplinar para a inovação. Cadernos de estudos avançados em design - sustentabilidade II, p. 13-29, 2009.

BROWN, T. Design Thinking: uma metodologia poderosa para decretar o fim das velhas idéias. Rio de Janeiro: Campus, 2010.

CARDOSO, Rafael. Design para um mundo complexo. São Paulo: Cosac Naify, 2012. 
DESCARTES, René. Discurso do método. Tradução de Paulo Neves. Porto Alegre: L\&PM, 2004.

ISHIHARA, Akemi Alessi. PROCESSOS METODOLÓgICOS PARA A PRÁTICA DE PROJETOS DE DESIGN PARA UM CONTEXTO SUSTENTÁVEL. 2014. 106 f. Dissertação (mestrado) - Universidade Estadual de Minas Gerais, Curso de Pós-Graduação em Design.

KOPP, Rudinei. Design gráfico cambiante. Santa Cruz do Sul: EDUNISC, 2004.

KRUCKEN, Lia. O Design e território: valorização de identidades e produtos locais. São Paulo: Studio Nobel, 2009.

LANA, Sebastiana Luiza Bragança. A complexidade dos métodos em design. Cadernos de estudos avançados em design - métodos, p. 53-65, 2011 (disponível em http://www.tcdesign.uemg.br/pdf/Metodo_completo.pdf)

MANZINI, Ezio e MERONI, Anna. Design em transformação. In: KRUCKEN, Lia. O Design e território: valorização de identidades e produtos locais. São Paulo: Studio Nobel, 2009.

MORAES, Dijon de. $O$ papel atual do design. In: KRUCKEN, Lia. O Design e território: valorização de identidades e produtos locais. São Paulo: Studio Nobel, 2009.

MORIN, Edgar. $O$ método 1: A natureza da natureza. Porto Alegre: Sulina, 2008

MUNARI, Bruno. Das coisas nascem coisas. São Paulo: Martins Fontes, 1998. 378 p.

VIANNA, Maurício...[et al.]. Design thinking: inovação em negócios. Rio de Janeiro: MJV Press, 2012. Disponível na internet por http em:

<http://livrodesignthinking.com.br/download/livro_dt_MJV.pdf>

WALKER, S. A journey in design: an exploration of perspectives for sustainability. The Journal of Sustainable Product Design. N. 2, p. 3-10, Netherlands: Kluwer Academic Publishers, Netherlands, 2002. 